\title{
Do doctors in north-western Somalia follow the national guidelines for tuberculosis management?
}

B.A. Suleiman, ${ }^{1}$ A.I. Houssein, ${ }^{2}$ F. Mehta ${ }^{3}$ and S. G. Hinderaker ${ }^{4}$

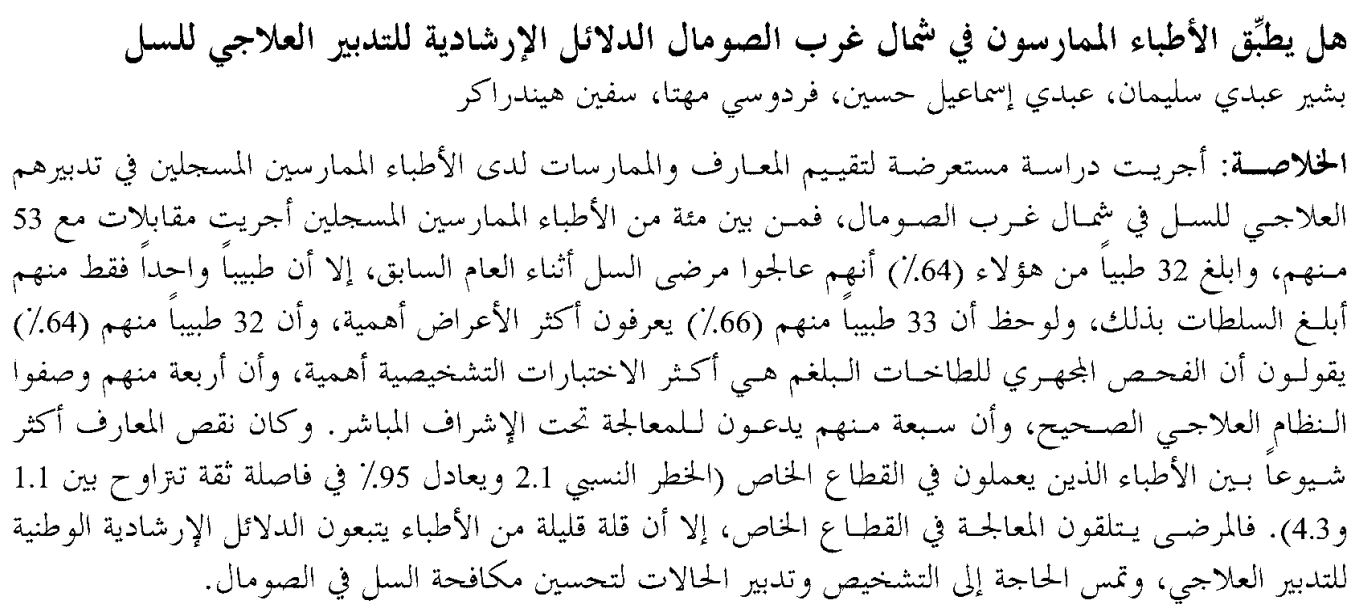

ABSTRACT A cross-sectional study assessed the knowledge and practices of registered practitioners in management of tuberculosis (TB) in north-western Somalia. Of 100 registered doctors, 53 were interviewed. Of these, $32(64 \%)$ had treated TB patients during the previous year, but only 1 had notified the authorities, $33(66 \%)$ knew the most important symptoms and $32(64 \%)$ identified sputum smear microscopy as the most important diagnostic test. Only 4 doctors prescribed the correct regimen and only 7 advocated direct observation. Suboptimal knowledge was more common among doctors working in private practice (relative risk: $2.1 ; 95 \% \mathrm{Cl}: 1.1-4.3$ ). Patients are being treated in the private sector, but few doctors follow national treatment guidelines. Training in diagnosis and case management is needed to improve TB control in Somalia.

\begin{abstract}
Les médecins dans le nord-ouest de la Somalie suivent-ils les directives nationales pour le traitement de la tuberculose?

RESUME Nous avons réalisé une étude transversale afin d'évaluer les connaissances et les pratiques des médecins diplômés en matière de traitement de la tuberculose dans le nord-ouest de la Somalie. Sur 100 médecins diplômés, 53 ont été interrogés. Parmi eux, 32 (64\%) avaient soigné des patients tuberculeux au cours de l'année précédente, mais un seul en avait informé les autorités ; 33 (66\%) connaissaient les symptômes les plus importants et $32(64 \%)$ désignaient la microscopie des frottis d'expectorations comme le test diagnostique le plus important. Seulement 4 médecins prescrivaient le schéma thérapeutique adéquat et seulement 7 préconisaient la surveillance médicale directe. Les connaissances non optimales étaient plus courantes chez les médecins exerçant en pratique privée (risque relatif : 2,$1 ;$ IC $95 \%: 1,1-4,3$ ). Les patients sont soignés dans le secteur privé, mais peu de médecins suivent les directives thérapeutiques nationales. Une formation au diagnostic et à la prise en charge des cas est nécessaire pour améliorer la lutte contre la tuberculose en Somalie.
\end{abstract}

${ }^{1}$ World Health Organization, Hargeisa, Somalia.

${ }^{2}$ Hargeisa General Hospital, Hargeisa, Somalia.

${ }^{3}$ World Health Organization (Somalia), Nairobi, Kenya.

${ }^{4}$ Centre for International Health, University of Bergen, Bergen, Norway.

المجلة الصحية لشرق المتوسط، منظمة الصحة العالمية، المجلد التاسع، العدد ع، ب... 


\section{Introduction}

In north-western Somalia, the private sector contributes significantly in providing health care, including the management of tuberculosis (TB) patients. The burden of TB in Somalia is considerable, with 2500 smear-positive pulmonary TB patients notified in 2000 in north-western Somalia only (excluding the rest of Somalia), corresponding to a rate of 162 per 100000 population [1] While many of the TB patients are treated within the national TB programme, observations at TB clinics have indicated that a number of the patients coming from the private sector were not given treatment in line with the national TB programme guidelines [2]. The knowledge and practices of medical doctors in the region, however, have not been documented through proper studies. In many other countries, the knowledge and practices of medical practitioners regarding TB has been appalling $[3,4]$.

Our objective was to determine the knowledge and practices of medical practitioners in north-western Somalia with regard to the symptoms, diagnosis and case management of pulmonary TB, as defined and specified by the national TB management guidelines.

\section{Methods}

We carried out a cross-sectional survey interviewing medical practitioners using a structured questionnaire. The survey was done in north-western Somalia between July and November 2001. The eligible population included all the qualified medical practitioners in the region. A list of all the medical doctors registered by the authorities in 2001was obtained from the Ministry of Health and Labour and included both public and private sector practitioners. We intended to include all the 100 doctors on the list. We excluded doctors working for the national TB programme (7) and doctors who had no clinical work (2). Causes for non-participation were: being too busy (4), travel abroad (6), mental handicap (3), not reachable in the war-zone (10), participated in the pretest (3), imprisonment (1), and missed appointment (11). Information from 53 doctors was analysed.

We categorized the doctors into 3 groups: those working exclusively in the public sector, those working exclusively in the private sector and those working in both sectors.

The questionnaire was prepared in English, with sections for general information, qualifications, work area, number of patients seen and number of patients treated in the past 12 months. Questions about knowledge of the symptoms of pulmonary TB were regarded as correctly answered if they identified 3 of 6 major symptoms of the disease mentioned in the national TB programme guidelines. The knowledge of diagnostic procedures was regarded as correct if they ranked sputum microscopy higher than X-ray and other laboratory examinations. The regimen for smearpositive pulmonary TB cases was regarded as correct if it followed the national TB programme guidelines (2HREZ/4HR) [2].

We also asked about supervision of drug taking, tracing of patients who missed appointments, tracing of family contacts and notification of TB patients. The questionnaire was pre-tested and modified according to the experience obtained in the pilot study. Data collection was done by 2 of the authors, Dr Suleiman and Dr Houssein. We made an appointment with each doctor and before the interview, written consent for her/his participation was obtained. All towns in the region were visited except Lasanod, which could not be reached for security reasons.

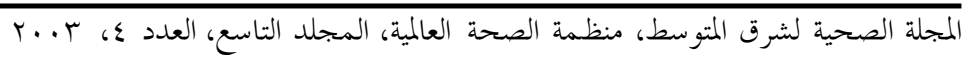




\section{Data management and analysis}

The interviewers scrutinized each other's completed questionnaires before data entry. Data entry was done in Epi-Info, version 6.04 by a team of 2 doctors and a clerk hired for data entry. Data entry validation was done. Cleaning of data was done before analysing with descriptive statistics. We also analysed potential risk factors for suboptimal knowledge of symptoms and diagnosis, and indicated the relative risks with $95 \%$ confidence intervals.

\section{Ethical considerations}

The research permit for this protocol was granted by the Ministry of Health and Labour, north-western Somalia. Written consent was obtained from each doctor before the interview, and confidentiality was maintained.

\section{Results}

We interviewed 53 doctors and the background characteristics are shown in Table 1. Of the 32 doctors who had treated a TB patient within the past 12 months, only 1 had submitted notification to the national TB programme. Table 2 shows the TB cases and the number of cases seen according to type of TB and type of practitioner. The survey showed that 36 doctors $(67.9 \%)$ indicated a correct combination of symptoms and 32 (64\%) indicated the correct diagnostic tests (Table 3 ). Only 4 doctors (7\%) indicated the correct regimen for smear-positive pulmonary TB, 24 (45\%) specified that drugs should be dispensed/ prescribed daily, and only 7 (13\%) that taking the drugs should be directly observed. Most doctors, 37 (69.8\%), indicated that pulmonary TB was suspected if the duration of the cough was 4 weeks or more. Eleven $(21 \%)$ doctors indicated that pa- tients who missed their appointments should be traced, and 6 (11\%) would try to look for TB among the contacts of the patient. Only 2 (4\%) reported that they had submitted a report after treating TB patients.

The potential risk factors for suboptimal knowledge about symptoms and diagnosis of pulmonary TB are shown in Table 4. Suboptimal knowledge of diagnosis of

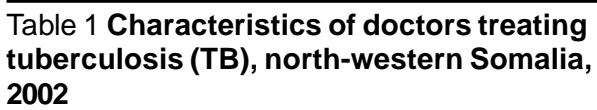

\begin{tabular}{lrr}
\hline Characteristic & $\begin{array}{c}\text { No. } \\
(\boldsymbol{n}=\mathbf{5 3})\end{array}$ & $\%$ \\
\hline Age (years) & & \\
$\quad<40$ & 10 & 19 \\
$40-49$ & 36 & 68 \\
$\quad 250$ & 7 & 13 \\
Sex & & \\
$\quad$ Male & 52 & 98 \\
$\quad$ Female & 1 & 2 \\
Year of graduation from & & \\
medical university & & \\
$\quad$ Before 1980 & 16 & 30 \\
$\quad$ 1980-1989 & 32 & 60 \\
$\quad$ 1990-2001 & 5 & 10 \\
$\quad$ Postgraduate training & & \\
$\quad$ specialist) & 20 & 38 \\
Work & & \\
$\quad$ Exclusively private & 17 & 32 \\
$\quad$ Exclusively public & 7 & 13 \\
$\quad$ Combined public and \\
private
\end{tabular}

NTP = national $T B$ programme

$n=$ total number of respondents

المجلة الصحية لشرق المتوسط، منظمة الصحة العالمية، المجلد التاسع، العدد ؟، ب.. 


\begin{tabular}{|c|c|}
\hline TB cases & Value \\
\hline $\begin{array}{l}\text { Total TB cases seen in past } 12 \text { months } \\
\text { [No. (\%) (mean per doctor)] }\end{array}$ & $1326(100 \%)(25)$ \\
\hline $\begin{array}{l}\text { Smear-positive pulmonary TB [No. (\%) (mean per } \\
\text { doctor)] }\end{array}$ & $142(11 \%)(3)$ \\
\hline $\begin{array}{l}\text { Smear-negative pulmonary TB [No. (\%) (mean per } \\
\text { doctor)] }\end{array}$ & $834(63 \%)(16)$ \\
\hline Extra-pulmonary TB [No. (\%) (mean per doctor)] & $350(26 \%)(7)$ \\
\hline $\begin{array}{l}\text { Median no. TB cases seen in past } 12 \text { months } \\
\quad(25-75 \text { percentile })\end{array}$ & $3(0-10)$ \\
\hline $\begin{array}{l}\text { Median no. TB cases seen in past } 12 \text { months by } \\
\text { private practitioners ( } 25-75 \text { percentile) }\end{array}$ & $6(1-12)$ \\
\hline $\begin{array}{l}\text { Median no. TB cases seen in past } 12 \text { months by } \\
\text { public sector doctors ( } 25-75 \text { percentile) }\end{array}$ & $0(0-9)$ \\
\hline $\begin{array}{l}\text { Median no. TB cases seen in past } 12 \text { months by } \\
\text { doctors working in both sectors ( } 25-75 \text { percentile) }\end{array}$ & $3(0-8)$ \\
\hline
\end{tabular}

pulmonary TB was more common among doctors working exclusively in the private sector (relative risk: $2.1,95 \%$ CI: 1.1-4.3) than among doctors working in both public and private sectors. Suboptimal knowledge about diagnosis was less common among doctors with no patients in the previous 12 months than among doctors with 10 or more in the same period (relative risk: 0.2 , $95 \%$ CI: 0.1-0.7).

\section{Discussion}

This study demonstrates that knowledge about modern TB management among doctors in north-western Somalia is not adequate. Although two-thirds of the doctors knew the major symptoms and the important diagnostic procedures, few indicated a correct treatment regimen. The results of this study indicate a lack of knowledge, which poses a threat to TB control in the country.
Poor knowledge and practice among doctors has been found in several studies. In Pakistan, only $38 \%$ relied on sputum smears as the main diagnostic tool, and only $7 \%$ knew the recommended treatment regimen [3]. A study in Hong Kong showed that over $50 \%$ of the doctors considered sputum smear not to be important in diagnosis of TB, and only $11 \%$ prescribed the recommended treatment regimen [4].

Doctors working exclusively in private practice more often had suboptimal knowledge about the diagnostic procedures of TB (relative risk: 2.1) than doctors working in both private and public sectors, and they were more likely to prefer $\mathrm{X}$-ray as the first choice investigation. The confidence interval was, however, fairly wide (95\% CI: 1.1-4.3). It may be that more patients going to the private sector demand $\mathrm{X}$-rays or it may be due to the unavailability of X-ray machines in the public sector. Doctors with no TB patients in the previous year were

المجلة الصحية لشرق المتوسط، منظمة الصحة العالمية، المجلد التاسع، العدد ع، ب... 
Table 3 Knowledge and practice in diagnosis and case management of tuberculosis (TB) among medical doctors in north-western Somalia, 2002

\begin{tabular}{|c|c|c|c|c|c|}
\hline \multirow[t]{2}{*}{ Knowledge/practice } & \multicolumn{2}{|c|}{$\begin{array}{l}\text { Non-specialist } \\
\quad(n=33)\end{array}$} & \multicolumn{2}{|c|}{$\begin{array}{l}\text { Specialist } \\
(n=20)\end{array}$} & \multirow[t]{2}{*}{$P$-value ${ }^{a}$} \\
\hline & No. & $\%$ & No. & $\%$ & \\
\hline Correct symptoms ${ }^{b}$ & 22 & 67 & 14 & 70 & 0.63 \\
\hline \multicolumn{6}{|l|}{$\begin{array}{l}\text { Duration of coughing arousing suspicion } \\
\text { of pulmonary } \mathrm{TB}^{\mathrm{c}} \text { (weeks) }\end{array}$} \\
\hline 2 & 2 & 6 & 2 & 10 & 0.33 \\
\hline 3 & 7 & 21 & 3 & 15 & \\
\hline 4 & 16 & 48 & 6 & 30 & \\
\hline$>4$ & 7 & 21 & 8 & 40 & \\
\hline No information & 1 & 3 & 1 & 5 & \\
\hline Correct priority of diagnostic test ${ }^{d}$ & 22 & 67 & 10 & 50 & 0.23 \\
\hline Correct treatment regimen & 3 & 9 & 1 & 5 & 0.22 \\
\hline \multicolumn{6}{|l|}{ Dispensing/prescribing of medicines } \\
\hline Daily & 16 & 48 & 8 & 40 & 0.74 \\
\hline Weekly & 5 & 15 & 2 & 10 & \\
\hline Monthly & 7 & 21 & 8 & 40 & \\
\hline Other & 1 & 3 & 0 & 0 & \\
\hline No information & 2 & 6 & 2 & 10 & \\
\hline Direct observation of medicine taking & 6 & 18 & 1 & 5 & 0.10 \\
\hline \multicolumn{6}{|l|}{ Correct action for patients missing } \\
\hline $\begin{array}{l}\text { appointments } \\
\text { Contact tracing }\end{array}$ & $\begin{array}{l}6 \\
4\end{array}$ & $\begin{array}{l}18 \\
12\end{array}$ & $\begin{array}{l}2 \\
2\end{array}$ & $\begin{array}{l}10 \\
10\end{array}$ & $\begin{array}{l}0.6 / \\
0.32\end{array}$ \\
\hline Submission of reports & 1 & 3 & 1 & 5 & 0.89 \\
\hline
\end{tabular}

${ }^{a} \mathrm{P}$-value of chi-squared test for difference between specialists and non-specialists. ${ }^{b}$ Correct symptoms were defined as a combination of 3 of 6 main symptoms mentioned in the national TB programme guidelines: cough, fever, chest pain, weight loss, night sweats, haemoptysis.

${ }^{c}$ According to national TB programme guidelines, 3 weeks or more.

${ }^{d}$ Sputum microscopy ranking before $X$-ray and other laboratory investigations was considered correct.

less likely to have suboptimal knowledge of diagnosis than doctors with higher caseloads (relative risk: 0.2 ). This is surprising and poses a threat as those doctors treating the greatest number of patients are the ones whose knowledge is most deficient.

The study covered more than $50 \%$ of registered doctors in north-western Somalia. Very few doctors refused to be interviewed, but a substantial number could not be reached for security reasons. The num- ber of doctors working in the region who are not registered with the ministry is unknown (we estimate around 20-40). We were not able to include them in the study. They may be working as private practitioners or for nongovernmental organizations. They are probably younger than the doctors registered in the ministry, with a higher proportion non-specialists. All these issues may to some extent limit the representativeness of the study.

المجلة الصحية لشرق المتوسط، منظمة الصحة العالمية، المجلد التاسع، العدد ع، ب... 


\begin{tabular}{|c|c|c|c|c|}
\hline \multirow[t]{2}{*}{ Potential risk factor } & \multicolumn{2}{|c|}{$\begin{array}{l}\text { Suboptimal knowledge } \\
\text { of TB symptoms }\end{array}$} & \multicolumn{2}{|c|}{$\begin{array}{l}\text { Suboptimal knowledge } \\
\text { of TB diagnosis }^{b}\end{array}$} \\
\hline & Relative risk & $95 \% \mathrm{Cl}$ & Relative risk & $95 \% \mathrm{Cl}$ \\
\hline \multicolumn{5}{|l|}{ Age of doctor (years) } \\
\hline$<40$ & Reference & - & Reference & - \\
\hline $40-49$ & 0.74 & $0.3-1.8$ & 0.5 & $0.2-1.0$ \\
\hline$\geq 50$ & 1.25 & $0.4-3.7$ & 1.1 & $0.5-2.4$ \\
\hline \multicolumn{5}{|l|}{ Work } \\
\hline Only private & 0.5 & $0.2-1.4$ & 2.1 & $1.1-4.3$ \\
\hline Only public & 0.3 & $0.1-2.1$ & 1.6 & $0.6-4.4$ \\
\hline Public + private & Reference & - & Reference & - \\
\hline \multicolumn{5}{|l|}{ Specialization } \\
\hline Postgraduate training & 0.8 & $0.4-1.9$ & 1.5 & $0.8-2.9$ \\
\hline No postgraduate training & Reference & - & Reference & - \\
\hline \multicolumn{5}{|l|}{ Town } \\
\hline Borama & 1.7 & $0.6-4.3$ & 0.3 & $0.1-2.1$ \\
\hline Burao & 1.0 & $0.3-2.9$ & 0.8 & $0.4-1.9$ \\
\hline Hargeisa & Reference & - & Reference & - \\
\hline Other & 1.7 & $0.5-5.0$ & c & \\
\hline \multicolumn{5}{|l|}{ TB case-load last year } \\
\hline None & 1.4 & $0.5-4.6$ & 0.2 & $0.1-0.7$ \\
\hline $1-9$ cases & 1.8 & $0.6-5.6$ & 0.9 & $0.5-1.6$ \\
\hline$\geq 10$ cases & Reference & - & Reference & - \\
\hline
\end{tabular}

The results of this study may have been influenced by several types of bias. There may be information bias in the study if the participants gave information which in reality they do not practise. They may prepare themselves for the interview, giving information in line with the guidelines, not reflecting their true (prior) practices. During the interviews we did not get that impression. There may also be selection bias if the non-participating doctors were different from the participants, e.g. those not following the guidelines may be more likely to refuse interview or not keep the appointment for the interview. We do not have enough background information on the non-participants to indicate a bias. Both of the above-mentioned biases would tend to show a better conformity with the guidelines than the reality. If so, the finding that only $7 \%$ follow the treatment guidelines may actually be an overestimation of the real situation, indicating a real need for a systematic approach to correcting this problem. 
With the current level of knowledge about TB case management, there is an environment which is conducive to the development of resistance to anti-TB drugs. There is clearly a need for the training of doctors in case detection and case management, in both the public and the private sectors.

\section{Acknowledgements}

This investigation received technical and financial support from the joint WHO Eastern Mediterranean Region (EMRO),
Division of Communicable Diseases (DCD) and the WHO Special Programme for Research and Training in Tropical Diseases (TDR): the EMRO/DCD/TDR Small Grants Scheme for Operational Research in Tropical and Communicable Diseases.

We would like to thank Professor D. Enarson, who kindly commented on the paper, and the Minister of Health and Labour who supplied the list of all registered medical doctors as well as the permit for conducting this study. We are also grateful to all the respondents who were willing to participate in the study.

\section{References}

1. Annual report of National TB programme, 2000. Nairobi, WHO-Somalia, 2001.

2. Guidelines for the management of tuberculosis in Somalia. Mogadishu, WHOSomalia 1994.

3. Rizvi N, Hussain M. Survey of knowledge about tuberculosis amongst family physicians. Journal of the Pakistan Medical Association, 2001, 51(9):333-7.

4. Hong YP et al. Survey of knowledge, attitudes and practices for tuberculosis among general practitioners. Tubercle and lung disease, 1995, 76(5):431-5.

المجلة الصحية لشرق المتوسط، منظمة الصحة العالمية، المجلد التاسع، العدد ؟، ب... 